\title{
Nicholas Agyepong $^{1}$, Christian Agyare ${ }^{1 *}$, Martin Adarkwa-Yiadom ${ }^{2}$, Stephen Yao Gbedema $^{1}$
}

${ }^{1}$ Department of Pharmaceutics, Faculty of Pharmacy and Pharmaceutical Sciences, Kwame Nkrumah University of Science and Technology, Kumasi, Ghana. ${ }^{2}$ Forensic Laboratory, Ghana Standards Authority, Accra, Ghana

*E-mail: cagyare.pharm@knust.edu.gh; chrisagyare@yahoo.com

\begin{abstract}
Background: Clausena anisata belongs to the family Rutaceae, a shrub widely used in West Africa for the treatment of bacterial and fungal infections of the skin including boils, ringworm and eczema. The study was designed to evaluate the antimicrobial activity and phytochemical screening of ethanol leaf extract of $C$. anisata (CLE).

Method: Antimicrobial activity of CLE was investigated using agar well diffusion and micro-dilution methods against four Gram-positive bacteria (Bacillus substilis NCTC 10073, Staphylococcus aureus ATCC 25923, Enterococcus faecalis ATCC 29212, Bacillus thuringiensis ATCC 13838) and two Gram-negative bacteria (Pseudomonas aeruginosa ATCC 4853, Proteus vulgaris ATCC 4175) and a clinical isolate of Candida albicans.

Results: CLE was active against all test organisms with minimum inhibitory concentration (MIC), range of 0.5 to $7.0 \mathrm{mg} / \mathrm{mL}$ against Gram-positive bacteria, 2.5 to $1.0 \mathrm{mg} / \mathrm{mL}$ against Gram-negative bacteria and $5.5 \mathrm{mg} / \mathrm{mL}$ against $C$. albicans. The MICs of the methanol fraction of CLE were $0.6 \mathrm{mg}$ to $5.0 / \mathrm{mL}$ and 1.0 to $3.0 \mathrm{mg} / \mathrm{mL}$ for Gram-positive and Gram-negative bacteria respectively. Chloroform fraction had MIC of 3.0 to $7.5 \mathrm{mg} / \mathrm{mL}$ and 2.0 to $6.5 \mathrm{mg} / \mathrm{mL}$ for Gram-positive and Gram-negative bacteria, respectively and petroleum ether fraction had 4.5 to $8.0 \mathrm{mg} / \mathrm{mL}$ for Gram-positive and Gram-negative bacteria. The CLE exhibited static action against all test organisms within a range of 0.5 to $22.0 \mathrm{mg} / \mathrm{mL}$. Phytochemical screening of $C$. anisata revealed the presence of tannins, flavonoids, steroids, saponins, glycosides and alkaloids. HPLC finger-printing of the CLE and its fractions were determined.
\end{abstract}

Conclusion: These results may justify the medicinal uses of $C$. anisata for the treatment of microbial infections.

Keywords: Phytochemical screening, antibacterial, antifungal, static action.

\section{Introduction}

Infectious diseases are major cause of death in tropical countries, accounting for approximately half of all fatalities (Lopez et al., 2006). In addition, its mortality rates are also increasing in developed countries (Pinner et al., 1996). These negative health trends are thought to be driven largely by socio-economic, environmental and ecological factors (Morens et al., 2000; Dassak et al., 2000; Woolhouse, 2008).

As a result of indiscriminate use of antibiotics in the treatment of these infectious diseases, microorganisms have developed resistance to many antibiotics (Cowan, 1999), and therefore the need to develop alternative antimicrobial agents. Medicinal plants have been shown to have genuine utility and about 70 to $80 \%$ of the rural population in most developing countries depends on medicinal plants for their primary health care (Akinyemi, 2005). Medicinal plants have been used as sources of remedies for the treatment of many diseases since ancient times by the people of all continents especially in the tropical regions.

Clausena anisata (Willd) Hooke, also known as horsewood or 'maggot killer' belongs to the family Rutaceae. It is a shrub that grows in forest and Savannah region of West Africa including Ghana and Nigeria. It is locally known in local Asante-Twi in Ghana as 'Ayida'. The leaves are used for the treatment of malaria (Uwaifo, 1984), worm infections, rheumatism, wounds (Hutchings et al., 1996; Okunade, 1987), skin infections including boils, ringworm, oral thrush and eczema (Hamza et al., 2006).

Compounds such as coumarins including furanocoumarins, imperatorin, oxypeucedanine and chalepin have been isolated from the root and stem bark (Chakraborty et al., 1995; Mester et al., 1997). A carbazole alkaloid, clausenol has been isolated from the ethanol extract of the stem bark and coumarins, limonoids, reducing sugars and alkaloids have been found in the stem bark (Chakraborty et al., 1995), and essential oils including $\beta$ pinene and sabinene chemotypes (Senthikumar and Venkatesalu, 2009), have been found in the leaves. The stem bark of $C$. anisata has been found to possess antimicrobial property (Chakraborty et al., 1995), anti-parasitic and central nervous depressant activity (Makanju, 1983), and root and stem bark exhibiting hypoglycaemic property (Ojewole, 2002). The aims of the study was to evaluate the antimicrobial activity of ethanol leaf extract of $C$. anisata and its methanol, chloroform and petroleum ether fractions against some microorganisms and also perform preliminary phytochemical screening on the ethanol extract and its fractions of $C$. anisata.

\section{Material and methods \\ Plant material}

The leaves of Clausena anisata were collected from the Physique Garden of Faculty of Pharmacy and Pharmaceutical Sciences, Faculty of Pharmacy and Pharmaceutical Sciences, Kwame Nkrumah university of Science and Technology, Kumasi, Ghana between October and November, 2010. The plant material was identified by Mr. G.H. Sam of the Department of Herbal Medicine, Kwame Nkrumah University of Science and Technology, Kumasi, Ghana with the voucher specimen number, KNUST/HML/2012/L 061. All chemicals and reagents were purchased from SigmaAldrich, Deisenhofen, Germany unless otherwise stated. 

http://dx.doi.org/10.4314/ajtcam.v11i3.28

\section{Test organisms}

Staphylococcus aureus NCTC 10788, Bacillus subtilis NCTC 10073, Pseudomonas aeruginosa ATCC 4853, Proteus vulgaris ATCC 4175, Bacillus thuringiensis ATCC 13838, Enterococcus faecalis ATCC 29212 were used as test organisms in the determination of antimicrobial activity of C. anisata extract and its fractions. Clinical isolates of Staphylococcus aureus, Enterococcus faecalis and Candida albicans obtained from the Bacteriology Unit of Komfo Anokye Teaching Hospital, Kumasi, Ghana and Pseudomonas aeruginosa and Proteus vulgaris were obtained from the Bacteriology Unit of Kumasi Centre for Collaborative Research (KCCR), Kwame Nkrumah University of Science and Technology, Kumasi, Ghana.

\section{Extraction procedure}

The fresh leaves of $C$. anisata were thoroughly washed with tap water, to remove dirt and soil particles. The plant material was air dried between 30 to $38^{\circ} \mathrm{C}$ for 5 days and then powdered using laboratory mill machine (Type 8, Christy and Norris Limited, United Kingdom). Two hundred (200), grams of powdered leaf material was added to $1000 \mathrm{~mL}$ of $70 \% \mathrm{v} / \mathrm{v}$ ethanol and extracted using cold maceration for $72 \mathrm{~h}$. This was subsequently filtered through Whatman filter paper Grade No. 10 (VWR International, Leuven, France). The filtrate was concentrated using rotary evaporator (Buchi Labortechnik AG, Germany), under $40^{\circ} \mathrm{C}$. The concentrated extract was lyophilized and the yield was determined.

The ethanol extract was subsequently fractionated sequentially with methanol, petroleum ether and chloroform using liquid-liquid separating method. Twenty (20), grams of the crude extract was dissolved in $100 \mathrm{~mL}$ methanol, shaken and sequentially extracted in non-polar, intermediate and polar fractions with $200 \mathrm{~mL}$ of petroleum ether, $200 \mathrm{~mL}$ of chloroform and $150 \mathrm{~mL}$ of methanol, respectively. The fractions obtained were concentrated under vacuum on rotary evaporator and dried below $40^{\circ} \mathrm{C}$. The yields for the crude ethanol extract, aqueous, pet ether and ethyl acetate fractions were $8.51,0.65,0.55$ and $0.64 \% \mathrm{w} / \mathrm{w}$ respectively (related to the dried plant material). The fractions obtained were kept in a desiccator.

\section{Phytochemical screening}

Preliminary phytochemical screening was performed on ethanol leaf extract of $C$. anisata (CLE), to determine the presence of tannins, flavonoids, anthraquinones, saponins, glycosides, terpenes and alkaloids (Wagner and Bladt, 1996; Harborne, 1998; Agyare et al., 2013). The total tannins content in the dried powdered leaf material was determined according to the method of Glasl, (1983) and Agyare et al. (2013), using pyrogallol (Merck, Darmstadt, Germany, purity $99.5 \%$, HPLC), as reference compound.

\section{Thin layer chromatography (TLC) of ethanol extract and fractions of C. anisata}

The ethanol extract, methanol, petroleum ether and chloroform fractions were analysed on thin layer chromatography (TLC) plate (silica gel $60 \mathrm{~F}_{254}$, Merck, Darmstadt, Germany). The extract and fractions $(10 \mathrm{mg} / \mathrm{mL})$ were spotted on the TLC and developed in acetone/petroleum ether (30:70), and observed in day light and under UV light $(254$ and $365 \mathrm{~nm})$. The TLC plate was sprayed with anisaldehyde reagent and observed under day light and UV light $(365 \mathrm{~nm})$. The retardation factor $\left(\mathrm{R}_{\mathrm{f}}\right)$ values of the separated spots/bands were determined.

\section{HPLC analysis of ethanol extract and fractions of $C$. anisata}

The HPLC analysis of CLE and its fractions were performed on a Thermo Finnigan HPLC system using Hypersil Gold $\mathrm{C}_{18}$, reversed-phase column $(150 \times 4.6 \mathrm{~mm})$. The concentration of CLE and fractions used for the analysis was $10 \mathrm{mg} / \mathrm{mL}$. The optimum HPLC conditions for the analysis were: injection volume: $10 \mu \mathrm{L}$, detection wavelength: $254 \mathrm{~nm}$, mobile phase: methanol: water $/ 50: 50$ (isocratic condition, temperature: $22^{\circ} \mathrm{C}$, pump pressure: $28 \mathrm{MPa}$, flow rate: $1 \mathrm{~mL} / \mathrm{min}$ and running time: $10 \mathrm{~min}$. The retention times for the various peaks for CLE and its fractions were determined.

\section{Antimicrobial activity}

The agar-well diffusion method as described by ver Poorte et al. (1988), was modified for the antimicrobial investigation. Two hundred micro-litre of $10^{6} \mathrm{cfu} / \mathrm{mL}$ of the test organisms was used to seed a $20 \mathrm{~mL}$ molten Mueller-Hinton agar (Oxoid, United Kingdom) stabilised at $45^{\circ} \mathrm{C}$ and aseptically transferred into sterile petri dish and allowed to set. Four wells equidistant from each other were made with a diameter of 10 mm for each well. The antimicrobial activity of the extract (CLE), and its fractions was determined at concentrations of 5.0, 15.0, 10.0 and 20.0 mg/mL. One hundred microliter $(100 \mu \mathrm{L})$, of each concentration was used to fill each well to three-quarters full and left to stand for $1 \mathrm{hr}$ to allow diffusion of the extract and its fractions into the seeded agar. The seeded Mueller-Hinton agar were then incubated at $37^{\circ} \mathrm{C}$ for $24 \mathrm{~h}$. Sabouraud agar (Oxoid, United Kingdom), was used as a medium for determination of antifungal activity of CLE and its fractions against C. albicans and then incubated at $37^{\circ} \mathrm{C}$ for $72 \mathrm{hrs}$. The zones of growth inhibition were recorded. The procedure was repeated three times for each test organism.

\section{Bio-autography assay}

Two twenty millilitre of Mueller-Hinton agar and sabouraud agar were melted at $100^{\circ} \mathrm{C}$, stabilized at $45^{\circ} \mathrm{C}$ and seeded with $0.1 \mathrm{~mL}$ of $S$. aureus and C. albicans $\left(10^{6} \mathrm{cfu} / \mathrm{mL}\right)$, respectively. The seeded gar was then spread in a thin film over a developed TLC plate of CLE and its fractions and then incubated at $37^{\circ} \mathrm{C}$ for $24 \mathrm{~h}$. After incubation, the plate was sprayed with $2.5 \mathrm{mg} / \mathrm{mL}$ thiazolyl blue tetrazolium bromide (MTT reagent). Bacterial and candidal growths of inhibition by bioactive constituents or bands were observed as a clear yellow zones or spots.

Determination of minimal inhibitory concentration (MIC), minimal bactericidal concentration (MBC) and minimum fungicidal concentration (MFC)

The MIC, MBC and MFC of CLE and its fractions were determined according to the modified method of Greenwood (1989). Concentrations of $0.4,0.8,1.6,3.2,6.25,12.5,25,25$ and $50 \mathrm{mg} / \mathrm{mL}$ ), were used. The test organism of $0.1 \mathrm{~mL}$ of $10^{6} \mathrm{cfu} / \mathrm{mL}$ was transferred into 10 $\mathrm{mL}$ test tubes containing the mixture of the broth and different concentrations of CLE or its fractions and then incubated at $37^{\circ} \mathrm{C}$ for $24 \mathrm{hrs}$. Two 
http://dx.doi.org/10.4314/ajtcam.v11i3.28

hundred micro-litres of $2.5 / \mathrm{mL}$ MTT were added to each medium. Bacterial growth inhibition was indicated as yellowish colouration whiles the presence of purple colour indicated bacterial growth. The MIC was recorded as the least concentration of extract/fraction which completely inhibited the growth of the test organism. MBC and MFC were determined as the minimum concentration of CLE and its fractions where no growth occurred when a small part of seeded agar without growth was streaked on nutrient agar (Oxoid, United Kingdom) and sabouraud agar for bacterial test organisms and C. albicans, respectively and then incubated at $37^{\circ} \mathrm{C}$ for $24 \mathrm{~h}$.

\section{Determination of time kill-kinetics}

The modified method of Spangler et al. (1997) was used for the determination of time-kill kinetics of CLE. Double strength nutrient broth (5 $\mathrm{mL}$ ) (Oxoid, United Kingdom) was used as a culture medium for this determination. The concentration of CLE used for the time kill kinetics against the selected test organisms was based on the increasing concentration of the MICs i.e. 1 x MIC, $2 \times$ MIC, $3 \times$ MIC and $4 \times$ MIC. Viable counts of the test organisms without the extract were first determined at $18 \mathrm{~h}$. Specific volumes were drawn from freshly prepared stock concentration of 100 $\mathrm{mg} / \mathrm{mL}$ of the extract (CLE) into the test tubes and sterile water added to make up $10.0 \mathrm{~mL}$ of concentration of $5.5,11.0,16.5 \mathrm{and} 22.0 \mathrm{mg} / \mathrm{mL}$ (against C. albicans). One hundred micro-litre of $10^{6} \mathrm{cfu} / \mathrm{mL}$ of the test organism was added to test tubes containing the various concentrations of the CLE. The test tubes were incubated at $37^{\circ} \mathrm{C}$ in a thermostatically controlled water bath with the shaker set at 40 shakes per min. The time kill kinetics was determined at $0,1,2,3,4,5,6,12$ and $24 \mathrm{hrs}$.

Exactly $1.0 \mathrm{~mL}$ volume of the reaction mixture was withdrawn at the appropriate time and transferred to $9.0 \mathrm{~mL}$ of normal saline to produce a 10 fold dilution to neutralize the effects of the CLE carry-over from the test suspensions. This was further diluted serially in two other 10 folds in sterile normal saline. One millilitre of the final dilution was aseptically transferred into a stabilised $20 \mathrm{~mL}$ molten count plate agar at $45^{\circ} \mathrm{C}$, poured into a petri dish, allowed to set and then incubated (inverted) at $37^{\circ} \mathrm{C}$ for $24 \mathrm{~h}$. The petri dishes were marked into segments and the colonies counted with the aid of a colony counter (Gerber Instruments, AG, and Holland). Each experiment was done in triplicate. Plates with 10 to 50 colonies were selected for counting. A graph of Log 10 of viable count against time was plotted to determine the time-kill kinetics. A control consisting of nutrient broth and the test organism without CLE was used as control in each experiment. The above procedure was repeated for the $C$. albicans with time intervals of $0,6,12,24,30,36,48,54$ and $72 \mathrm{~h}$.

\section{Results}

Antimicrobial activity of ethanol and the different solvent fractions against test organisms

The different fractions showed comparatively varying degrees of activity against the test organisms. The methanol and chloroform fractions showed significant activity compared to the petroleum ether fraction $(\mathrm{p}<0.05)$ at a concentrations of $20 \mathrm{mg} / \mathrm{mL}$ against $E$. faecalis and $S$. aureus. The

Table 1: Antimicrobial activity of ethanol leaf extract of $C$. anisata and its fractions against test organisms. The mean zones of growth inhibition were determined from three independent determinations $(n=3)$ for all test organisms. nd: not determined, SEM: standard error mean. * $<<0.05$ compared to antimicrobial activity of pet ether fraction.

\begin{tabular}{|c|c|c|c|c|c|}
\hline \multirow[t]{2}{*}{ Test organisms } & \multirow{2}{*}{$\begin{array}{l}\begin{array}{l}\text { Concentration } \\
(\mathrm{mg} / \mathrm{mL})\end{array} \\
\end{array}$} & \multicolumn{3}{|c|}{ Mean zones of growth inhibition \pm SEM } & \multirow[b]{2}{*}{ Methanol } \\
\hline & & Ethanol & Petroleum ether & Chloroform & \\
\hline \multirow{4}{*}{ E. faecalis } & 20.0 & $21.3 \pm 0.33$ & $17.3 \pm 0.33$ & $21.0 \pm 0.58 *$ & $24.0 \pm 0.58 *$ \\
\hline & 15.0 & $20.0 \pm 0.58$ & $16.3 \pm 0.67$ & $19.0 \pm 0.33$ & $22.0 \pm 0.88$ \\
\hline & 10.0 & $17.4 \pm 0.33$ & $14.3 \pm 0.34$ & $17.3 \pm 0.66$ & $19.3 \pm 0.33$ \\
\hline & 5.0 & $15.8 \pm 0.33$ & $11.7 \pm 0.33$ & $14.3 \pm 0.67$ & $16.6 \pm 0.67$ \\
\hline \multirow{4}{*}{ B.subtilis } & 20.0 & $20.0 \pm 0.0$ & $13.3 \pm 0.33$ & $14.0 \pm 0.58$ & $18.7 \pm 0.33^{*}$ \\
\hline & 15.0 & $17.5 \pm 0.33$ & $11.3 \pm 0.33$ & $13.3 \pm 0.57$ & $16.6 \pm 0.33$ \\
\hline & 10.0 & $16.7 \pm 0.33$ & 0.0 & $11.3 \pm 0.33$ & $14.3 \pm 0.33$ \\
\hline & 5.0 & $13.0 \pm 0.0$ & 0.0 & $11.0 \pm 0.0$ & $11.3 \pm 0.0$ \\
\hline \multirow{4}{*}{ P. aeruginosa } & 20.0 & $19.1 \pm 0.58$ & $16.7 \pm 0.88$ & $15.3 \pm 0.33$ & $18.3 \pm 0.33^{*}$ \\
\hline & 15.0 & $17.8 \pm 0.68$ & $12.7 \pm 0.33$ & $13.7 \pm 0.33$ & $16.3 \pm 0.33$ \\
\hline & 10.0 & $16.0 \pm 0.58$ & $11.3 \pm 0.33$ & $12.3 \pm 0.33$ & $13.3 \pm 0.33$ \\
\hline & 5.0 & $14.3 \pm 0.33$ & 0.0 & $11.3 \pm 0.33$ & $11.7 \pm 0.33$ \\
\hline \multirow{4}{*}{ S. aureus } & 20.0 & $20.8 \pm 0.33$ & $17.3 \pm 0.33$ & $20.3 \pm 0.33^{*}$ & $20.4 \pm 0.57 *$ \\
\hline & 15.0 & $18.3 \pm 0.33$ & $15.7 \pm 0.33$ & $17.1 \pm 0.33$ & $17.3 \pm 0.33$ \\
\hline & 10.0 & $16.7 \pm 0.67$ & $14.3 \pm 0.33$ & $15.3 \pm 0.33$ & $15.7 \pm 0.33$ \\
\hline & 5.0 & $14.0 \pm 0.58$ & $11.7 \pm 0.33$ & $12.7 \pm 0.33$ & $13.6 \pm 0.34$ \\
\hline \multirow{4}{*}{ P. vulgaris } & 20.0 & $18.0 \pm 0.58$ & $16.6 \pm 0.31$ & $17.0 \pm 0.57$ & $22.6 \pm 0.11 *$ \\
\hline & 15.0 & $16.3 \pm 0.33$ & $14.3 \pm 0.33$ & $14.7 \pm 0.33$ & $19.3 \pm 0.33$ \\
\hline & 10.0 & $15.0 \pm 0.0$ & $13.3 \pm 0.11$ & $13.5 \pm 0.57$ & $17.3 \pm 0.33$ \\
\hline & 5.0 & $13.0 \pm 0.58$ & $12.7 \pm 0.33$ & $13.3 \pm 0.33$ & $13.1 \pm 0.11$ \\
\hline \multirow[t]{4}{*}{ B. thuringiensis } & 20.0 & $18.7 \pm 0.33$ & $12.7 \pm 0.33$ & $13.7 \pm 0.67$ & $16.0 \pm 0.58^{*}$ \\
\hline & 15.0 & $17.0 \pm 0.0$ & $11.0 \pm 0.0$ & $12.6 \pm 0.67$ & $14.7 \pm 0.33$ \\
\hline & 10.0 & $14.7 \pm 0.33$ & 0.0 & $11.3 \pm 0.33$ & $12.3 \pm 0.33$ \\
\hline & 5.0 & $13.0 \pm 0.58$ & 0.0 & 0.0 & $11.0 \pm 0.0$ \\
\hline \multirow{4}{*}{ C. albicans } & 20.0 & $20.3 \pm 0.33$ & $15.3 \pm 0.33$ & $15.1 \pm 0.31$ & $15.6 \pm 0.33$ \\
\hline & 15.0 & $19.0 \pm 0.0$ & $13.0 \pm 0.58$ & $12.7 \pm 0.33$ & $13.3 \pm 0.33$ \\
\hline & 10.0 & $17.0 \pm 0.0$ & 0.0 & $11.3 \pm 0.33$ & $11.7 \pm 0.33$ \\
\hline & 5.0 & $15.3 \pm 0.33$ & 0.0 & $11.0 \pm 0.0$ & $10.6 \pm 0.0$ \\
\hline
\end{tabular}




\section{http://dx.doi.org/10.4314/ajtcam.v11i3.28}

Methanol fraction showed significant activity compared to chloroform and petroleum ether fractions $(\mathrm{p}<0.05)$ at $20 \mathrm{mg} / \mathrm{mL}$ against all test organisms except $C$. albicans. Though the ethanol extract exhibited a broad spectrum of activity, it was more active against the Gram-positive bacteria than Gram-negative bacteria within the different concentrations used (Table 1).

\section{Phytochemical screening of ethanol leaf extract of $C$. anisata}

Phytochemical screening of ethanol leaf extract of $C$. anisata revealed the presence of tannins, alkaloids, steroids, saponins, phenolics, flavonoids, cardiac glycosides and anthraquinones glycosides. Terpenes were not detected. The tannin content was $1.48 \%$ w/w (related to the dried leaf material).

\section{HPLC of $C$. anisata ethanol leaf extract and fractions}

The HPLC chromatograms of ethanol leaf extract (CLE) and its fractions were used as finger-printing for the identification of major constituents (peaks) and quality control purposes. The chromatograms showed different peaks of compounds for ethanol extract and its fractions within 10 min retention time (Figure 2 to 5 ).

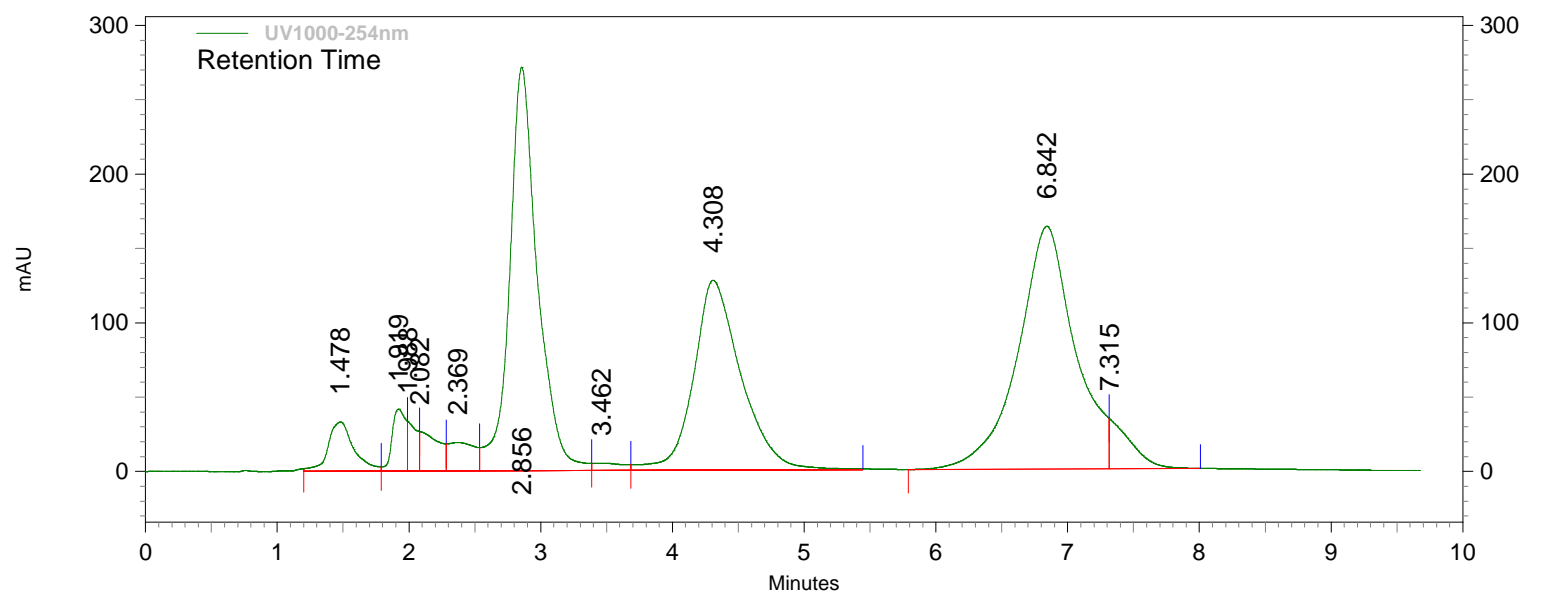

Figure 2: HPLC chromatogram of the ethanol leaf extract (CLE) at $\kappa 254 \mathrm{~nm}$.

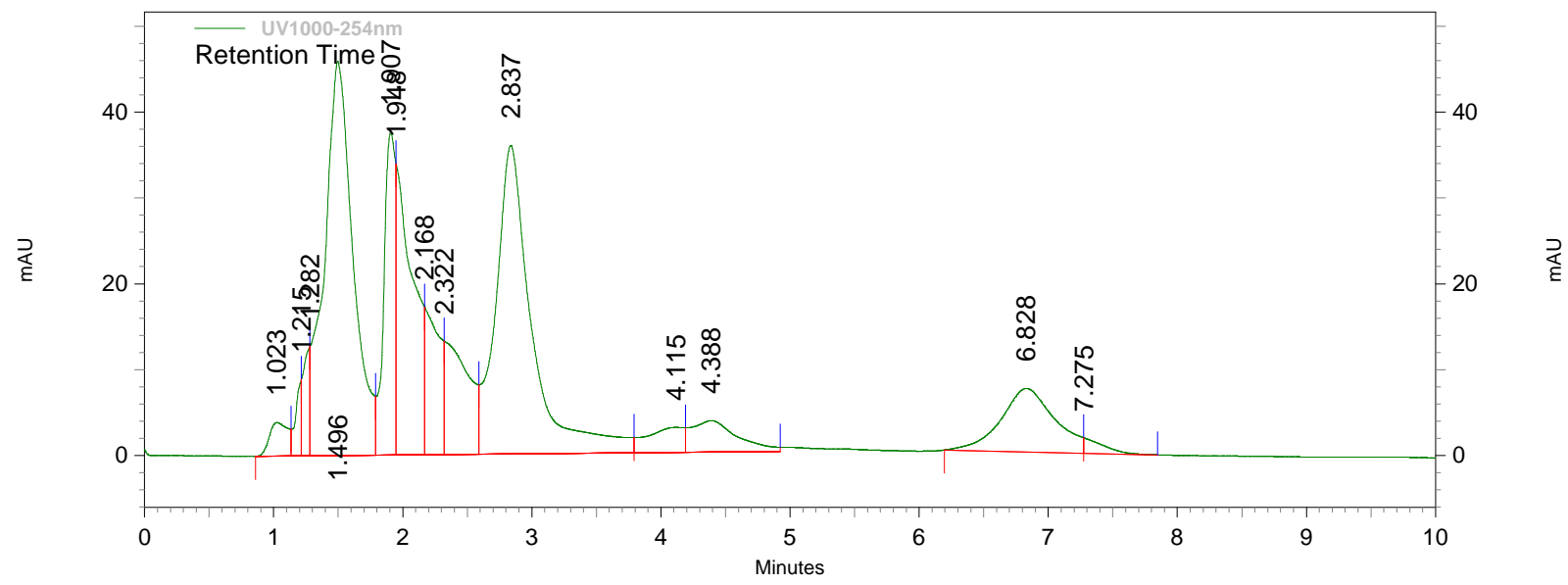

Figue 3: HPLC chromatogram of the methanol fraction of the CLE at $\kappa 254 \mathrm{~nm}$. 


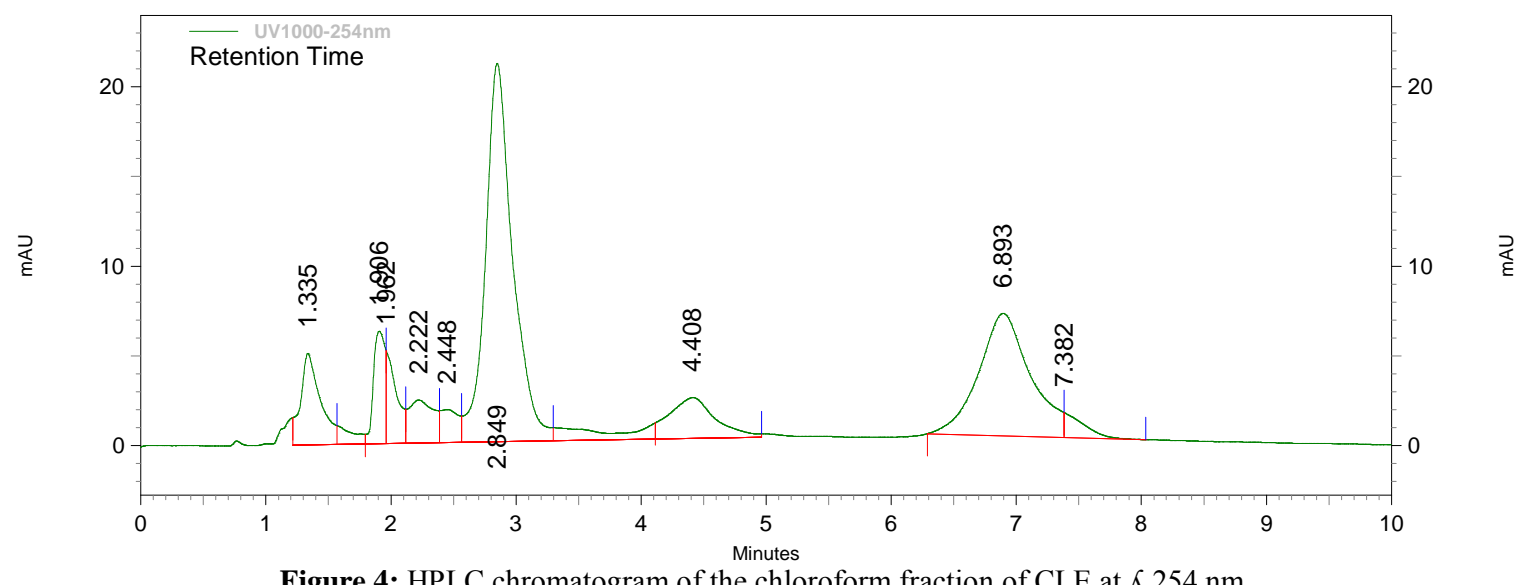

Figure 4: HPLC chromatogram of the chloroform fraction of CLE at $\kappa 254 \mathrm{~nm}$.

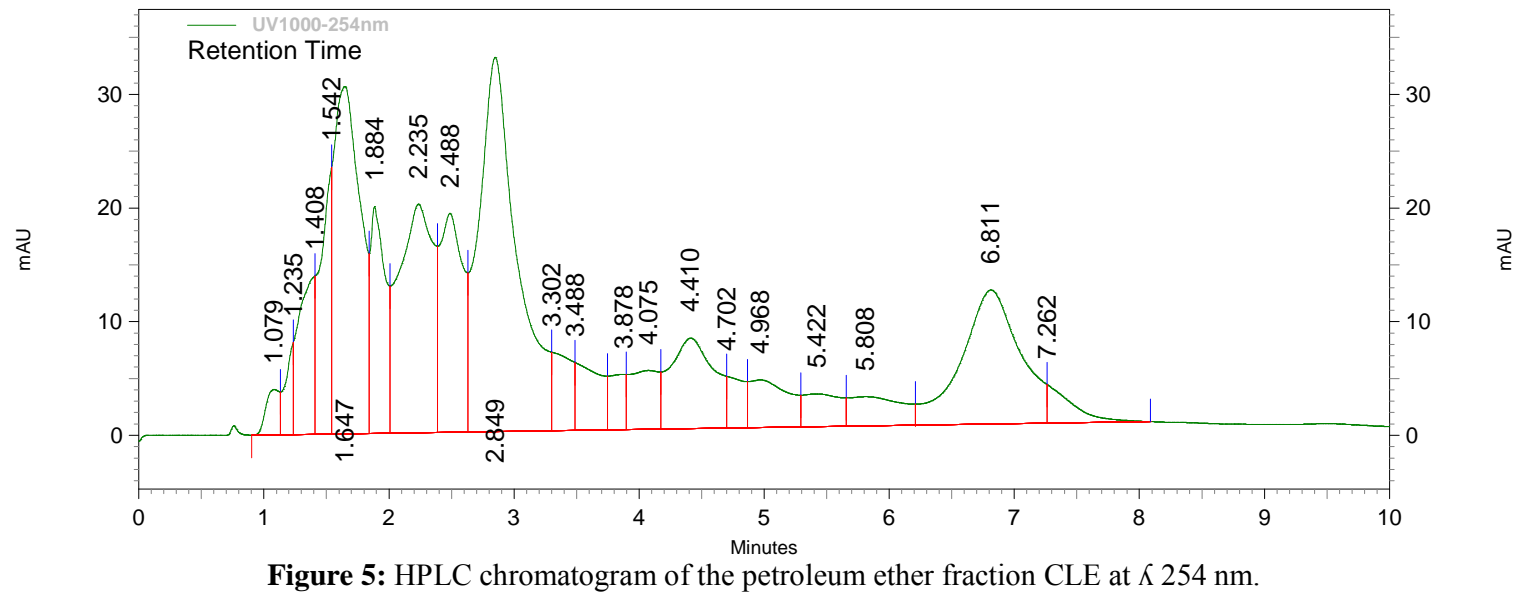

Thin layer chromatography (TLC) of ethanol leaf extract of .C anisata and fractions

Thin layer chromatography of the ethanol leaf extract and its fractions revealed various bands (indicating different constituents/compounds) under UV light (254 and 365nm). The pet ether, chloroform and methanol fractions revealed a number of characteristics bands which could be used in the identification of the extracts or the plant material (Fig. 6). The bands (compounds) showing characteristic blue fluorescence at $365 \mathrm{~nm}$ with $\mathrm{R}_{\mathrm{f}}$ of values 0.83 and 0.24 ) were found to be present in the ethanol extract and the various fractions could be used as preliminary identification of the $C$. anisata leaf extract and its fractions.

Table 2: Mean zones of growth inhibition of ethanol leaf extract of C. anisata against test organisms

\begin{tabular}{|c|c|c|c|c|c|c|c|}
\hline \multirow[b]{2}{*}{$\begin{array}{c}\text { Concentration } \\
\text { of extract } \\
(\mathrm{mg} / \mathrm{mL})\end{array}$} & \multicolumn{7}{|c|}{ Mean zones of inhibition $(\mathbf{m m})+$ SEM } \\
\hline & P. aeruginosa & P. vulgaris & B. thuringiensis & $\begin{array}{l}S . \\
\text { aureus }\end{array}$ & $\begin{array}{l}\text { E. } \\
\text { faecalis }\end{array}$ & B. subtilis & C. albicans \\
\hline \multirow[t]{2}{*}{20.0} & 19.00 & 18.00 & 18.67 & 20.67 & 21.33 & 20.00 & 20.33 \\
\hline & \pm 0.58 & \pm 0.58 & \pm 0.33 & \pm 0.33 & \pm 0.33 & \pm 0.00 & \pm 0.33 \\
\hline \multirow[t]{2}{*}{15.0} & 17.67 & 16.33 & 17.00 & 18.33 & 20.00 & 17.33 & 19.00 \\
\hline & \pm 0.68 & \pm 0.33 & \pm 0.00 & \pm 0.33 & \pm 0.58 & \pm 0.33 & \pm 0.00 \\
\hline \multirow[t]{2}{*}{10.0} & 16.00 & 15.00 & 14.67 & 16.00 & 17.33 & 16.33 & 17.00 \\
\hline & \pm 0.58 & \pm 0.00 & \pm 0.33 & \pm 0.00 & \pm 0.33 & \pm 0.33 & \pm 0.00 \\
\hline \multirow[t]{2}{*}{5.0} & 14.33 & 13.00 & 13.00 & 14.00 & 15.33 & 13.00 & 15.33 \\
\hline & \pm 0.33 & \pm 0.58 & \pm 0.58 & \pm 0.58 & \pm 0.33 & \pm 0.00 & \pm 0.33 \\
\hline \multirow{2}{*}{$\begin{array}{l}\text { Ciprofloxacin } \\
(0.002)\end{array}$} & 20.50 & 21.80 & 24.50 & 23.50 & 25.60 & 19.10 & nd \\
\hline & \pm 0.67 & \pm 0.68 & \pm 0.33 & \pm 0.33 & \pm 0.58 & \pm 0.11 & \\
\hline \multirow{2}{*}{$\begin{array}{l}\text { Ketoconazole } \\
(0.002)\end{array}$} & nd & nd & nd & nd & nd & nd & 30.00 \\
\hline & & & & & & & \pm 0.11 \\
\hline
\end{tabular}

The mean zones of growth inhibition was determined from three independent result $(n=3)$ for all test organisms. nd: not determined, SEM: standard error mean. 


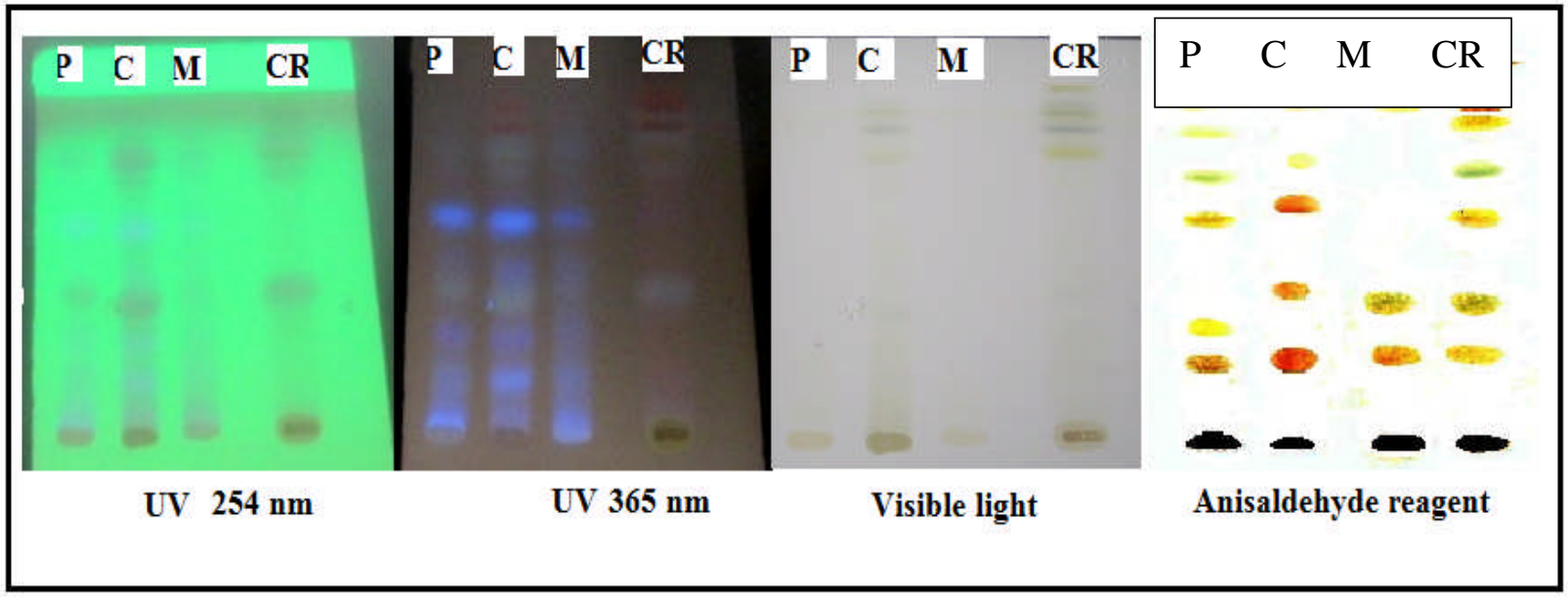

Figure 6: The TLC chromatogram of ethanol extract and fractions. Thin layer chromatogram of crude ethanol extract (CR), methanol (M), petroleum ether (P) and chloroform (C) fractions visualised under UV (254 and 365nm), day light and sprayed with anisaldehyde reagent. Six (6) prominent bands were revealed under the UV light of the ethanol crude extract. The petroleum ether, chloroform, and methanol fractions showed 6, 5 and 3 spots respectively under the same condition. This is due to the maximum absorbance of the compound.

\section{Bio-autography}

The active constituents/compounds from the developed TLC of ethanol leaf extract of $C$.anisata and its fractions exhibited zones of growth inhibition against $S$. aureus and $C$. albicans. The appearance of yellow spots indicate inhibition of growth of the test organisms, S. aureus (Fig. 7A) and C. albicans (Fig. 7B), respectively.

A

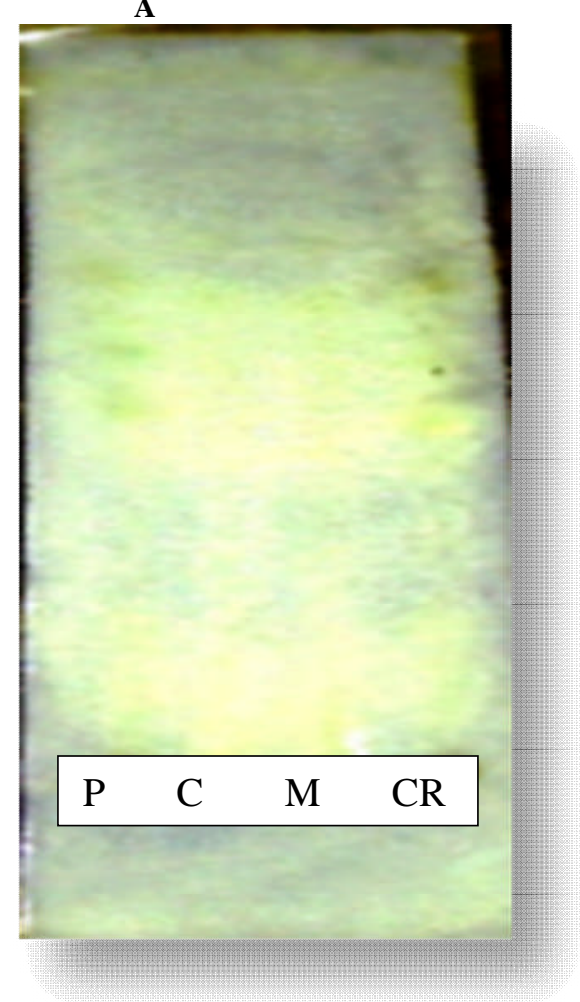

B

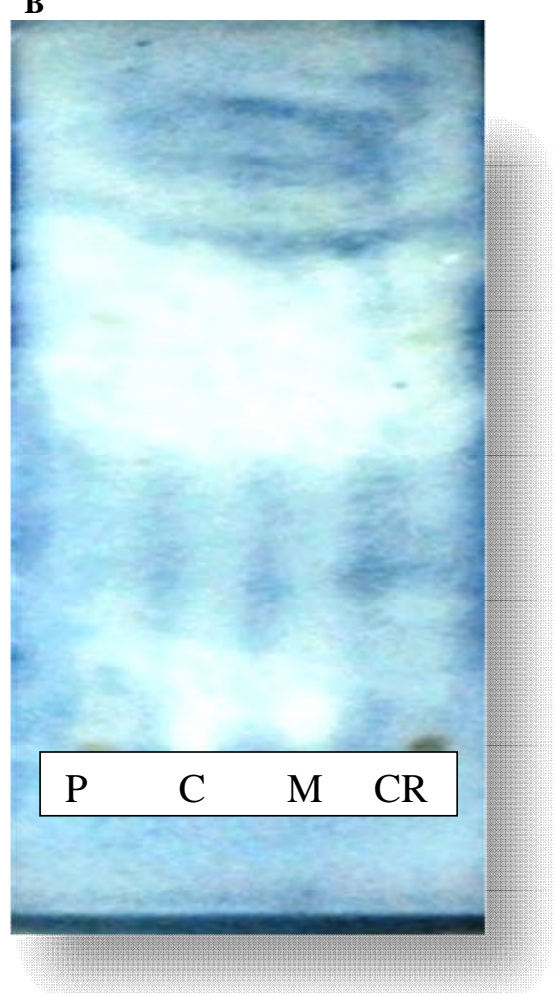

Figure 7: Bio-autography of ethnol extract and fractions of $C$. anisata. The bio-autography showed zones of growth inhibition against $S$. aureus (A) and $C$. albicans $(\mathbf{B})$. The zones of bacteria growth inhibition were visible as yellow clear areas against purple background after spraying with MTT. Crude ethanol leaf extracts $(\mathbf{C R})$, methanol $(\mathbf{M})$, petroleum ether $(\mathbf{P})$ and chloroform $(\mathbf{C})$ fractions. 
http://dx.doi.org/10.4314/ajtcam.v11i3.28

Antimicrobial activity of ethanol extract by agar diffusion method

The ethanol leaf extract exhibited a broad spectrum of activity against the test organisms. It was more active against the Gram-positive bacteria than Gram-negative bacteria for both typed and clinical strains at all the different concentrations (Table 2).

\section{Antimicrobial activity of the different fractions of ethanol leaf extract of $C$. anisata}

The different fractions of CLE showed comparatively varying degrees of activity against the test organisms. The methanol and chloroform fraction showed a higher activity than petroleum ether fraction at the concentrations of $20 \mathrm{mg} / \mathrm{mL}$ against E. faecalis (EF), and $S$. aureus (SA). The methanol fraction exhibited higher activity than chloroform and petroleum ether fractions at $20 \mathrm{mg} / \mathrm{mL}$ against the test organisms except $C$. albicans (Fig. 8).

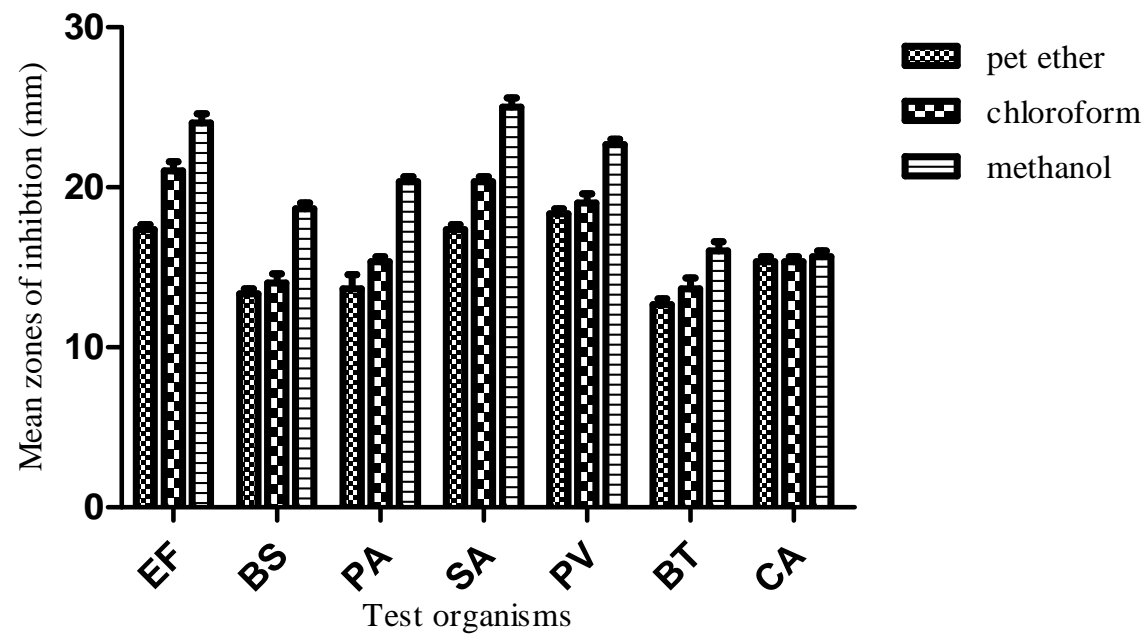

Figure 8: Mean zones of inhibition of different fractions $(20 \mathrm{mg} / \mathrm{ml})$ of ethanol leaf extract of $C$. anisata. The mean zones of growth inhibition was determined from three independent result $(\mathrm{n}=3)$ for all test organisms. Test organisms: E. faecalis $(\mathrm{EF})$, B. subtilis $(\mathrm{BS}), S$. aureus $(\mathrm{SA})$ P. aeruginosa (PA), P. vulgaris (PV), B. thurigiensis (BT) and C. albicans (CA).

Minimum Inhibitory Concentration and Minimum Bactericidal Concentrations (MICs/MBCs) of the ethanol extract and fractions

The ethanol leaf extract of $C$. anisata gave different MICs and MBCs against the test organisms. There were relatively lower MICs for Gram-positive bacteria compared with the Gram-negative bacteria with the ethanol extract exhibited highest activity against the Gram-positive bacteria (Table 3). The methanol fraction showed highest activity against the test organisms as compared with chloroform and petroleum fractions based on the MICs (Table 4).

Table 3: MICs and MBCs of the ethanol extract by broth macro-dilution technique

\begin{tabular}{|c|c|c|c|c|}
\hline \multirow[t]{2}{*}{ Test Organisms } & \multicolumn{2}{|c|}{ Ethanol Extract } & \multirow{2}{*}{$\begin{array}{c}\text { Ciprofloxacin } \\
\text { MIC }(\mu \mathrm{g} / \mathrm{mL})\end{array}$} & \multirow{2}{*}{$\begin{array}{l}\text { Ketoconazole } \\
\text { MIC }(\mu \mathrm{g} / \mathrm{mL})\end{array}$} \\
\hline & MIC (mg/mL) & $\mathrm{MBC}(\mathrm{mg} / \mathrm{mL})$ & & \\
\hline E. faecalis & 4.5 & 19.0 & 25.0 & nd \\
\hline B. subtilis & 0.5 & 4.0 & 20.0 & nd \\
\hline S. aureus & 0.9 & 15.0 & 20.0 & nd \\
\hline P. aeruginosa & 2.5 & 11.0 & 40.0 & nd \\
\hline P. vulgaris & 1.0 & 14.0 & 25.0 & nd \\
\hline B. thuringiensis & 1.5 & 17.0 & 30.0 & nd \\
\hline C. albicans & 5.5 & 27.5 & $\mathrm{Nd}$ & 2.5 \\
\hline \multirow{2}{*}{\multicolumn{5}{|c|}{ di: not determined }} \\
\hline & & & & \\
\hline \multirow[t]{2}{*}{ Test Organisms } & \multicolumn{3}{|c|}{ MIC $(\mathbf{m g} / \mathbf{m L})$} & \\
\hline & \multicolumn{2}{|c|}{ Methanol fraction } & Chloroform fraction & Pet ether fraction \\
\hline E. faecalis & \multicolumn{2}{|c|}{2.0} & 6.5 & 8.0 \\
\hline B. subtilis & \multicolumn{2}{|c|}{0.6} & \multirow{2}{*}{$\begin{array}{l}3.0 \\
3.0\end{array}$} & 4.5 \\
\hline S. aureus & \multicolumn{2}{|c|}{1.5} & & 4.5 \\
\hline$P$. aeruginosa & \multicolumn{2}{|c|}{2.0} & $\begin{array}{l}3.0 \\
4.5\end{array}$ & 4.0 \\
\hline P. vulgaris & \multicolumn{2}{|c|}{1.0} & 2.0 & 2.5 \\
\hline B. thuringiensis & \multicolumn{2}{|c|}{5.0} & 7.5 & 6.5 \\
\hline C. albicans & \multicolumn{2}{|c|}{5.0} & 7.0 & 10.0 \\
\hline
\end{tabular}

Time kill kinetics 


\section{http://dx.doi.org/10.4314/ajtcam.v11i3.28}

The time-kill kinetics studies conducted showed bacteriostatic and fungi-static activities at the different concentrations of the ethanol extracts against all the test bacteria and C. albicans, respectively (Figures 9 to 11).

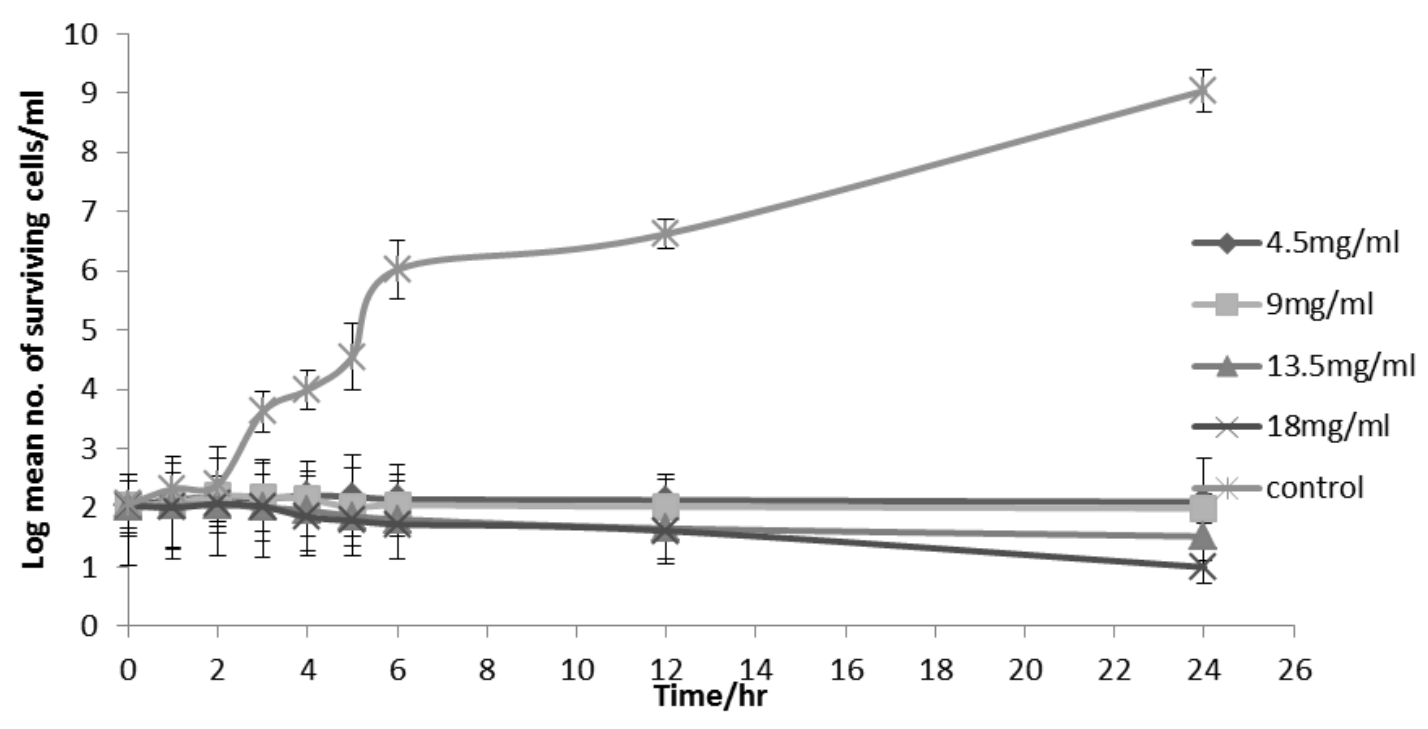

Figure 9: Survival of $E$. faecalis in extract at different concentrations of $C$. anisata within 24 h. Control: Broth culture of $E$. faecalis without the extract.

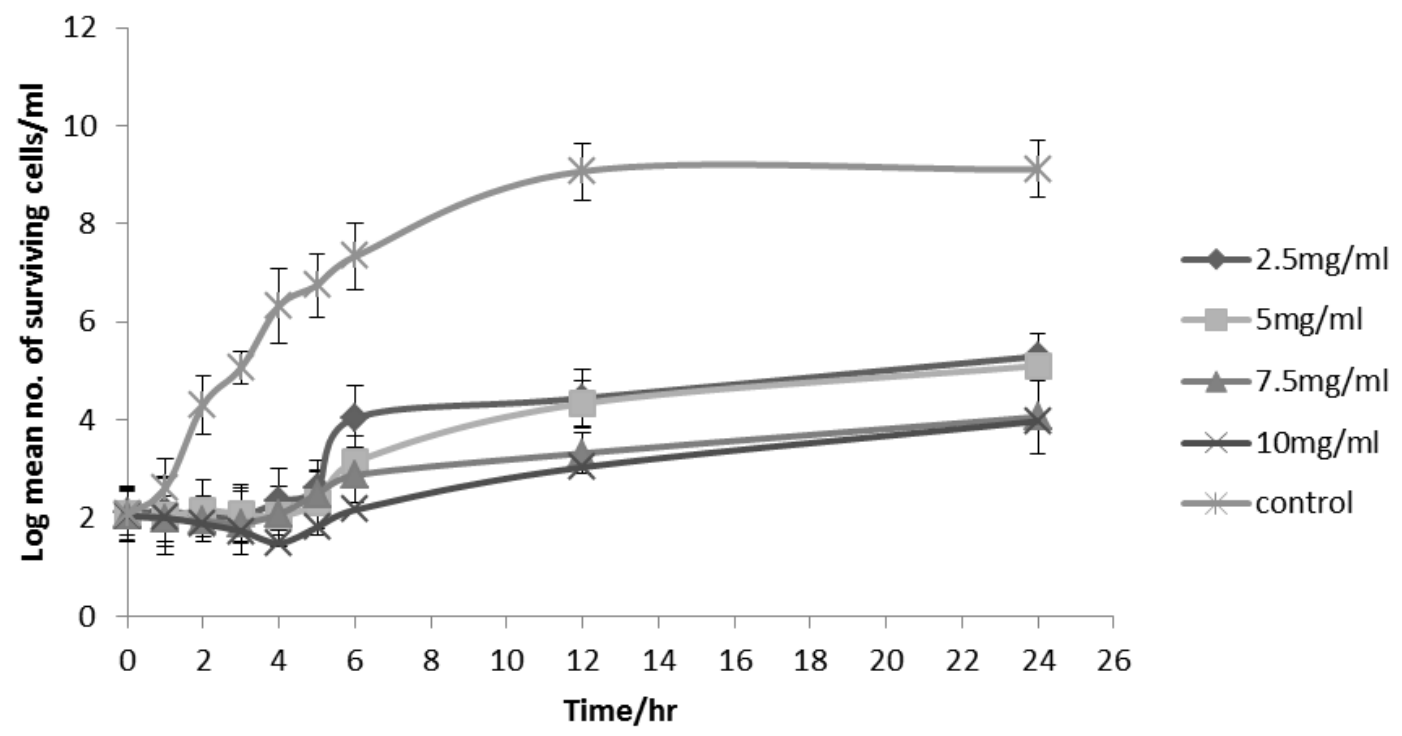

Figure 10: Survival of $P$. aeruginosa in extract at different concentrations of $C$. anisata within 24 h. Control: Broth culture of $P$. aeruginosa without the extract. 


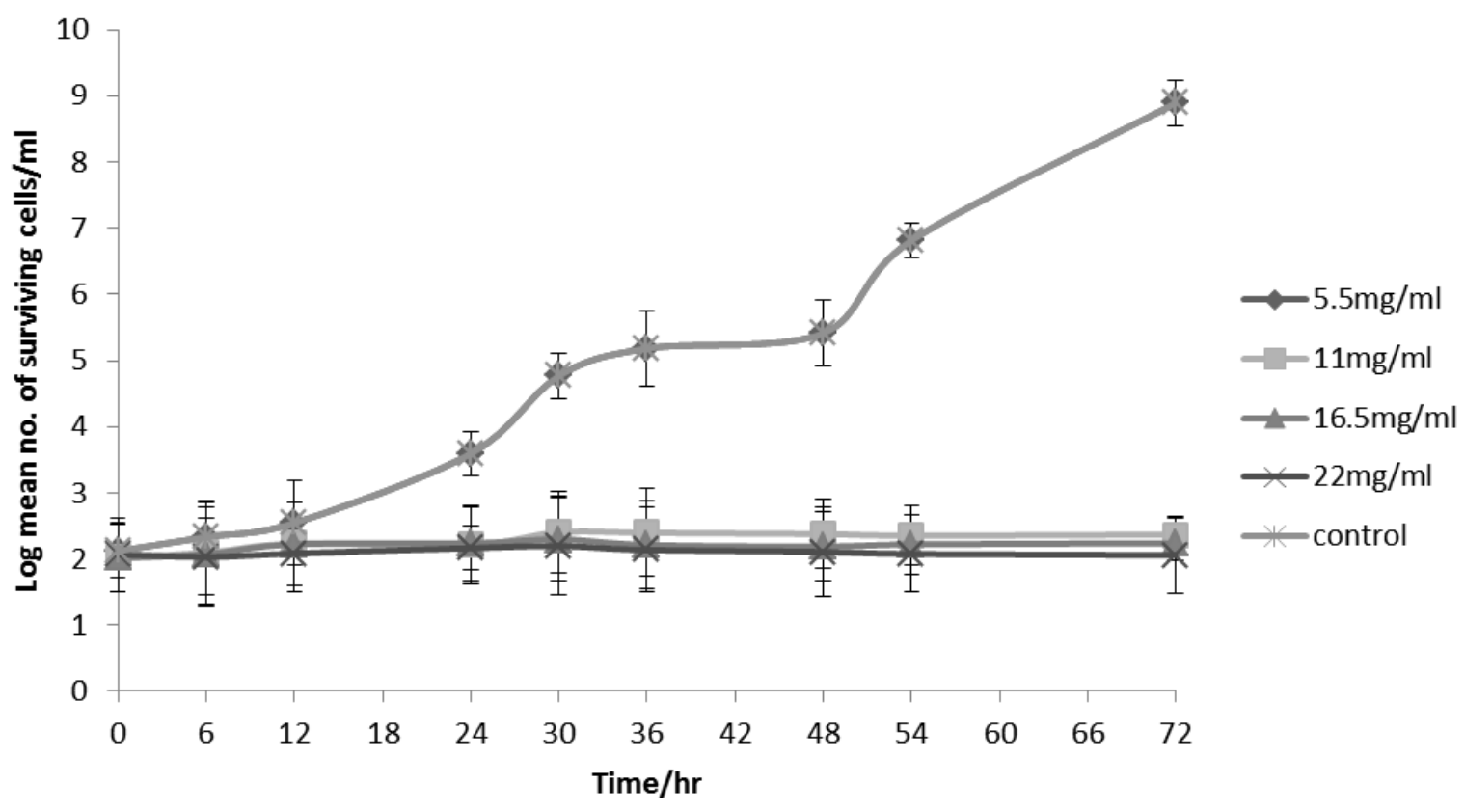

Figure 11: Survival of C. albicans in extract at different concentrations of $C$. anisata within 24 h. Control: Broth culture of $C$. albicans without the extract.

\section{Discussion}

Traditional medical practitioners use a variety of herbal preparations for either the treatment or management of different kinds of microbial infections. The leaves of $C$. anisata is one of such plants used by the traditional healers for the treatment or management of various skin infections, ulcers, sores and other microbial infections (Hamza et al., 2006).

The ethanol leaf extract and its fractions showed varying degrees of antimicrobial activities against the test organisms with ethanol leaf extract exhibited the highest activity at the same concentration (Figure 8). Plant extracts from organic solvents have been reported to give more consistent antimicrobial activity compared to water extract (Parekh et al., 2005). Hence ethanol could be a better solvent for bioactive constituents of leaves of $C$. anisata. The antimicrobial activity exhibited by CLE and its fractions may justify the use of the leaf of the plant for the treatment and management of infectious diseases by the traditional healers.

Preliminary phytochemical screening of ethanol leaf extract of $C$. anisata showed the presence of tannins, saponins, flavonoids, steroids, phenolics, anthraquinonnes, glycosides, cardiac glycosides and alkaloids. Phytochemical constituents such as flavonoids have been found in vitro to be effective against a wide range of microorganisms (Harborne, 1993; Owoyele et al., 2008). Tannins and saponins have been reported to prevent the growth of microorganisms by precipitating microbial protein and making nutritional proteins unavailable for them (Sodipo et al., 1991; Panda and Tripathy, 2009). Studies have also shown that the growth of many fungi, bacteria and viruses are inhibited by tannins (Chung et al., 1998; Panda and Tripathy, 2009) and the presence of flavonoids, tannins and saponins in the ethanol leaf extract could therefore be responsible for the antimicrobial properties of the C. anisata.

The presence of flavonoids was confirmed on the TLC chromatogram by the characteristic yellow fluorescence bands at $365 \mathrm{~nm}$ in the pet ether, chloroform and methanol fractions on the TLC. The inhibition of growth on bio-autography TLC plates by the ethanol extract and fractions against the S. aureus and C. albicans indicates that antimicrobial constituents or principles are present in both non-polar and polar solvents (Figure 7). The HPLC of ethanol extract and its fractions revealed a number of characteristics peaks (constituents) which could be used in the identification of the plant material.

There was no significant difference in the antimicrobial activity of the petroleum ether and chloroform fractions. However, there was significant difference between the activity of the methanol fraction exhibiting the highest activity than the petroleum ether and chloroform fractions at the concentration of $20 \mathrm{mg} / \mathrm{mL}$ against the test organisms. The ethanol leaf extract gave MIC range of 0.5 to $5.5 \mathrm{mg} / \mathrm{mL}$ against test organisms. Senthilkumar and Venkatesalu (2009) reported that the essential oil extracted from the leaves of $C$. anisata had MIC of 0.250 to $0.125 \mathrm{mg} / \mathrm{mL}$ against similar test organisms except $C$. albicans.

The time kill kinetics of the $C$. anisata ethanol extracts against test organisms gave variable effect among the test organisms (Figures 9 to 11). The extracts exhibited static activity and therefore the time kill kinetics was observed as the reduction of the number of cells of the test organisms by the inhibitory effect of the ethanol leaf extract of $C$. anisata. There was a high reduction for E. faecalis from 12 to $24 \mathrm{~h}$ by CLE at the concentration of $18.0 \mathrm{mg} / \mathrm{mL}$ (Figure 9). Further isolation, purification and structural elucidation of the bioactive compounds responsible for the antimicrobial activity of ethanol leaf extract of $C$. anisata would be carried out.

\section{Conclusion}

The ethanol leaf extract of $C$. anisata and its fractions exhibited antimicrobial activity with static action against all test organisms with MIC range of 0.5 to $10.0 \mathrm{mg} / \mathrm{mL}$. Phytochemical screening of ethanol leaf extract of $C$. anisata revealed the presence of tannins, alkaloids, steroids, 


\section{http://dx.doi.org/10.4314/ajtcam.v11i3.28}

saponins, phenolics, flavonoids, cardiac glycosides and anthraquinones glycosides. HPLC finger-printing of the ethanol leaf extract and the various fractions were developed. The individual or the additive or synergistic effects of the phytochemical constituents present in the $C$. anisata leaf extract may be responsible for antibacterial and antifungal properties and may justify use of the plant for treatment of microbial infections.

\section{Acknowledgements}

The authors are grateful to the technical staff of Departments of Pharmacognosy and Pharmaceutics (Microbiology Section), Faculty of Pharmacy and Pharmaceutical Sciences, Kwame Nkrumah University of Science and Technology, Kumasi, Ghana for their assistance.

Conflict of Interest: Authors declare that they have no competing interests.

\section{References}

1. Agyare, C., Koffour, G.A., Boakye, Y.D., and Mensah, K.B. (2013). Antimicrobial and anti-inflammatory properties of Funtumia elastica. Pharm Biol. 51(4):418-25.

2. Akinyemi, K.O., Oladapo, O., Okwara, C.C., and Kehinde, A.F. (2005). Screening of crude extracts of six medicinal plants used in South-West Nigerian unorthodox medicine for anti-methicillin resistant Staphylococcus aureus activity. BMC Complem Altern Med. 5(6):1472-1478.

3. Chakraborty, A., Chowdhury, B.K., and Bhattacharyaa, K. (1995). Clausenol and clausenine-two carbazole alkaloids from Clausena anisata. Phytochem, 40(1):295-298.

4. Cowan, M.M.(1999). Plant products as antimicrobial agents. Clin Microbiol Rev. 12 (4):564-582.

5. Chung, K.T., Wong, T.Y., Wei, C.I., Huang, Y.W., and Lin, Y. (1998). Tannins and human health: A review. Crit Rev Food Sci Nutr. 38 (6): $421-464$.

6. Daszak, P., Cunningham, A.A., and Hyatt, A.D. (2000). Emerging infectious diseases of wildlife-threats to biodiversity and human health. Science, 287:443-449.

7. Glasl, H. (1983). Zur Photometrie in der Drogenstandiserung, Deutscher Apotheker Zeitung (DAZ). 123, 1979-1987.

8. Greenwood, D. (1989). Antibiotic Sensitivity Testing. Inc: Antimicrobial Chemotherapy, Greenwood, D (Ed.). Oxford University Press, New York. pp. 91-100.

9. Hamza, O.J., van den Bout-van den Beukel, C.J., Matee, M.I., Moshi, M.J., Mikx, F.H., Selemani, H.O., Mbwambo, Z.H., van der Ven, A.J. and Verweij, P.E. (2006). Antifungal activity of some Tanzanian plants for the treatment of fungal infections. J Ethnopharmacol. 108 (1):124-132.

10. Harborne, J.B. (1993). Phytochemical method, $3^{\text {rd }}$ Ed. Chapman and Hall Ltd, London. pp. 60-66, 135-203.

11. Hutching, A., Scoh, A.H., Lewis, G., and Cunningham, A. (1996). Clausena anisata (Willd). Hook. F. ex Benth. Zula Medicinal Plants: An inventory, University of Natal Press, Pietermaritzury, South Africa, pp 153-154.

12. Lopez, A.D., Mathers, C.D., Ezzati, M., Jamison, D.T., and Murray, C.J.L. (2006). Global and regional burden of disease and risk factors: systematic analysis of population health data. Lancet 367: 1747-1757.

13. Makanju, O.O.A. (1983). Behavioural anticonvulsant effect of an aqueous extract from the roots of Clausena anisata Rutaceae. Int J Crude Drug Res. 66: 543-547.

14. Mester, J., Szendrei, K., and Reisch, J. (1997). Constituents of Clausena anisata. Planta Med. 32: 81-85.

15. Morens, D.M., Folkers, G.K., and Fauci, A.S. (2004). The challenge of emerging and re-emerging infectious diseases. Nature. 430: $242-249$.

16. Okunade, A.L. (1987). Estragole: An acute toxic principle from the volatile oil of the leaves of Clausena anisata. J Nat Prod., 50(5): 990-991.

17. Ojewole, J.A. (2002). Hypoglycemic effect of Clausena anisata (Wild). Hook. f. ex Benth. methanolic root extract in rats. J Ethnopharmacol. 81 (2): 231-237.

18. Owoyele, V.B., Adediji, J.O., and Soladoye, A.O. (2005). Anti-inflammatory activity of aqueous leaf extracts of Chromolaena odorata. Inflammopharmacol. 13:479-484.

19. Panda, P., and Tripathy, G. (2009). Wound healing activity of aqueous and methanolic bark extract of Vernonia arborea in Wistar rats: Nat Prod Radiance. 8:6-11.

20. Parekh, J., Jadeja, D., and Chanda, S. (2005). Efficacy of aqueous and methanol extracts of some medicinal plants for potential antibacterial activity. Turk J Biol. 29:203-210.

21. Pinner, R., Teutsch, S., Simonsen, L., Klug, L., Graber, J., Clarke, M., and Berkelman, R. (1996). Trends in infectious diseases mortality in the United States. J Am Med Assoc. 275, 189-193.

22. Senthilkumar, A., and Venkatesalu, V. (2009). Phytochemical analysis and antibacterial activity of the essential oil of Clausena anisata (Willd.) Hook. f. ex Benth. Int J Integr Biol. 5 (2): 116-120.

23. Sodipo, O.A., Akanji, M.A., Kolawole, F.B., and Odutuga, A.A. (1991). Saponin is the active antifungal principle in Garcinia kola, heckle seed. Biosci Res Commun. 3: 171

24. Spangler, S.K., Jacobs, M.R., and Appelbaum, P.C. (1997). Bactericidal activity of DU-6859a compared to activities of three quinolones, three $\beta$ lactams, clindamycin, and metronidazole against anaerobes as determined by time-kill methodology. Antimicrob Agents Chemother. 41: $847-849$.

25. Uwaifo, A.O. (1984). The mutagencities of seven coumarin derivatives and a furan derivative (nimbolide) isolated from three medicinal plants. J Toxicol Environ. 56(3):117-121.

26. Verpoorte, R., Grand, L., and Pousset, J. (1998). Anti-infectives and phytototherapies of the tree savanna of Senegal. J Ethnopharmacol. 22(1):25-31.

27. Woolhouse, M.E.J. (2008). Epidemiology of Emerging diseases go global. Nature. 451, 898-899.

28. Wagner, H., and Bladt, S. (1996). Plant drug analysis: A thin layer chromatography, 2nd ed, Springer Verlag, New York. 